\title{
Teresa-M. Sala
}

\section{LES ARTS A ESCENA: L'EXPERIÈNCIA DEL TEATRE DE NATURA ${ }^{1}$}

Pel tema a l'esperit;

Pel color als ulls i l'esperit;

Per la música a l'orella i a l'esperit encara.

Adrià GuAL

\section{Preludi}

En els esdeveniments o espectacles de caràcter audiovisual, la captació de la llum i I'espai pren cos amb l'escoltar i el mirar o el sentir i el veure, ${ }^{2}$ tot dirigint-se, segons Gual, vers I'esperit. Amb el moviment romàntic havien emergit temes com les personificacions de les forces naturals, la supremacia del sentiment i el trencament amb les teories imitatives de la tradició. A partir de la influència de Richard Wagner, les arts escèniques integraren literatura, música i escenografia. A finals del segle XIX, els efectes sinestèsics de llum, color, moviment i musicalitat van revolucionar la posada en escena. Aquests canvis estètics, conjuntament amb les innovacions tècniques, buscaven alterar la recepció convencional per part dels espectadors. En el moviment simbolista s'esdevé un lligam important amb els wagnerians, i així és que, del cercle del poeta Stéphane Mallarmé, Édouard Dujardin va fundar la Revue wagnérienne, des de la qual es va difondre l'esperit integrador del compositor alemany. Tanmateix, com assenyala Jordi Coca:

[...] la síntesi de les arts la veien plenament realitzada en la música i aspiraven a dur-la a terme en la poesia a través dels procediments, de les «correspondències», encetats per Baudelaire; en canvi estaven plens de recels pel teatre on, segons ells, els actors, els decorats, el temps real de la representació, la carnalitat, en una paraula, els impedien d'arribar netament als seus propòsits. $^{3}$

De fet, en gran mesura, amb algunes de les propostes dels simbolistes s'inicia la modernitat. La influència de Maurice Maeterlinck suposa fer
Matèria, núm. 12, 2017, ISSN 1579-2641, p. 113-128

Recepció: 16-1-2017

Acceptació: 6-6-2017

1 S'inscriu en el projecte de recerca «Biologia i simbolisme a la Barcelona del 1900» (HAR2012-35921) de GRACMON-UB finançat pel Ministeri $d^{\prime}$ Economia i Competitivitat.

2 Sobre les relacions entre el veure i el saber, vegeu John Berger, Modos de ver, BarceIona, Gustavo Gili, 2000 (1974).

3 Jordi COCA, «Els simbolistes i Wagner» a «Introducció» dins Quatre variacions sobre la mort. La intrusa, Els cecs/Interior/La mort de Tintagiles de Maurice Maeterlinck, Barcelona, Biblioteca Teatral-Institut del Teatre-Ed. del Mall, 1984, p. 8. 
4 Les obres La intrusa i Interior de Maurice Maeterlinck es van representar respectivament al Cau Ferrat i a Barcelona.

5 Adrià Gual. Mitja vida de Modernisme, Barcelona, Diputació de Barcelona-Àmbit serveis editorials, 1992.

6 Carles BAtLle, Adrià Gual (1891-1902): per un teatre simbolista, Barcelona, Curial, 2001.

7 Adrià GuAL, «El teatre popular», Joventut, III (1901), p. 309.

8 En aquests plafons de l'Associació Wagneriana destaquen el vaixell $d^{\prime}$ Isolda, el port de Cornualla, I'espera del rei Marke, el camí del Grial o el castell i el jardí de Klingsor. Vegeu el catàleg de I'exposició, Lourdes Jiménez, Richard Wagner i Adrià Gual. Els plafons perduts de l'Associació Wagneriana, Museu d'Història de Catalunya, 2013. Mostra que, després de sortir de la programació de l'Arts Santa Mònica, recorre algunes de les obres produïdes sota la influència de la passió wagneriana i que reprodueixen la iconografia de les òperes del compositor alemany.

9 Edouard Bertouy, Castelbon de Beauxhostes. L'âge d'or du spectacle lyrique aux arènes de Béziers, Éditions du Mont, 2007.

10 Palmira GonzÁlez, Els anys daurats del cinema clàssic a Barcelona (1906-1923), Barcelona, Publicacions de I'Institut del Teatre de la Diputació de Barcelona i Edicions 62, 1987; Joan M. Minguet, "La "Sala Mercè" de Lluís veure més enllà de les aparences que capten els sentits i dirigir la mirada vers una realitat ignota. ${ }^{4}$ A Catalunya, Adrià Gual ha estat considerat el gran renovador de I'escena catalana. ${ }^{5}$ Com bé ha estudiat Carles Batlle, en la seva primera etapa es nota la tendència integradora de les seves propostes. ${ }^{6}$ I, tal com ell mateix escriu en la revista Joventut, I'interès per prendre la llegenda i la cançó popular com a nucli inspirador per a la construcció del teatre modern s'arrela en els grecs, Shakespeare, Goethe o Wagner. ${ }^{7}$

El projecte cultural de Gual des de la plàstica s'endinsa en el món de I'espectacle teatral, que no s'entén sense la música. La via escènica com a possibilitat d'assolir l'ideal de l'art total s'expressa en I'obra Nocturn. Andante morat (1896) i en Blancaflor (1899), que són una mostra del drama musical i el teatre popular, mentre que Silenci (1898) o La culpable (1899) copsen el drama de món, una experiència artística que pretén trobar I'essència catalana d'uns conflictes que són universals. D'altra banda, els quadres plàstics que Gual va fer en benefici de la restauració de Sant Cugat del Vallès o els dotze plafons decoratius dedicats a Parsifal i Tristany i Isolda per a I'Associació Wagneriana són una mostra més de les temptatives escenicodecoratives de les temàtiques de les obres. ${ }^{8}$

Entre 1893 i 1896, els pintors de I'anomenada Colla del safrà (Adrià Gual, Isidre Nonell, Joaquim Mir, Ricard Canals, Juli Vallmitjana i Ramon Pichot) recorren els camps de Sant Martí de Provençals i pinten els paisatges de tons safranosos. També el teatre va sortir dels edificis per representar-se a l'aire lliure. Atès que Gual era amic del productor d'obres teatrals francès Castelbon de Beauxhostes, va voler portar a territori català representacions plein-air com les que s'havien dut a terme a partir des del 1898 fins al 1911 a la ciutat occitana de Besiers, ${ }^{9}$ anomenada en els diaris de l'època com la «Bayreuth française». Per allà van desfilar els cantants i intèrprets de París i de la Scala més prestigiosos, amb composicions musicals de Saint-Saëns, Fauré o Déodat de Séverac.

Seguint aquest model, Adrià Gual va muntar als jardins del Laberint del comte d'Alfarràs a Horta, amb la collaboració de Miquel Utrillo, la tragèdia Ifigènia a Tàurida de Johann Wolfgang von Goethe, que originàriament havia estat representada als jardins del palau de la cort de Weimar. Va estrenar-se el 10 d'octubre de 1898 en català, a partir d'una traducció de Joan Maragall. El públic assistent hi acudí amb prèvia invitació, i l'estrena constituí la primera escenificació del Teatre Íntim; a més, el 23 de gener de 1899 es va tornar a representar al Teatre Líric.

En aquesta línia, una de les manifestacions més interessants d'espectacle total la va dur a terme el pintor Lluís Graner amb l'obertura de la Sala Mercè. ${ }^{10}$ Allà es feien sessions diàries de cinema «parlat» $i$ «quadres plàstics musicals». S'hi van instal.lar unes grutes fantàstiques construïdes 
per Antoni Gaudí, que eren una mostra de naturalesa artificial, amb un marcat accent pintoresc. Tal com remarcava la premsa, va convertir-se en un espectacle capriciós:

[...] de las grutas subterráneas con sus estalactitas y estalagmitas, construidas con sólo hierro y cemento, con el acierto y perfección que dan verdadera idea de lo natural. Los efectos de luz son preciosos y las figuras del Nacimiento y la de Juan Garín, son del escultor Clarassó. Una cascada de agua natural contribuye con su murmullo a producir en aquella quietud el efecto de hallarse en plena naturaleza. ${ }^{11}$

De manera simultània, entre 1905 i 1907, als Espectacles i Audicions Graner al Teatre Principal van participar-hi els músics més rellevants del panorama líric català, per exemple Enric Morera, Enric Granados, Felip Pedrell i Jaume Pahissa. És allà on Adrià Gual va escenificar una «visió de naturalesa» intitulada La matinada, amb música del mestre Felip Pedrell i decorats d'Oleguer Junyent, una obra que en certa manera preludia l'experiència del que s'havia d'anomenar Teatre de Natura.

\section{La consagració del projecte Teatre de Natura}

Entre 1910 i 1917 es va propagar per Catalunya I'anomenat Teatre de Natura, amb representacions que es van dur a terme a Figueres, Sabadell, la Garriga, Badalona, el Montseny, Vallvidrera i Barcelona, organitzades per intel-lectuals i artistes rellevants. ${ }^{12}$ Aquí ens interessa descobrir l'essència d'aquest tipus d'espectacle, l'ideal poètic i el caràcter d'identitat que el distingeix enfront d'altres obres de «teatre a la fresca», en què la natura és només un teló de fons. Per la seva rellevància, hem cregut adient centrar I'anàlisi en les representacions de Canigón ${ }^{13}$ de Jacint Verdaguer, Flors de Cingle d'Ignasi Iglésias i Rondalla bosquetana. La viola d'or d'Apel.les Mestres.

A diferència dels teatres antics de la tragèdia clàssica a I'aire lliure - espais circulars construïts a cel obert - el Teatre de Natura, segons explicita Gabriel Alomar, és "un teatre natural» que té un component essencial de natura escenificada. Tanmateix, el teatre grec no era un edifici - cosa que en certa manera es recupera amb les experiències de teatre plein air a França-. No obstant, cal considerar que el jardí del segle XIX havia introduït un nou concepte lúdic en aquest tipus d'espai naturalitzat, i aquí la fruïció visual transita per jocs de perspectives diferents i canviants. Tot plegat, seguint la descripció d'Alomar, confereix a la representa-
Graner (1904-1908): un epígon del Modernisme?», D'Art. Revista del Departament d'Història de l'Art de la Universitat de Barcelona, núm. 14, III/1988; Jordi CASTELLANOS, «Dolor, renúncia i mort: el misteri de l'amor», Els Marges, 93. Hivern 2011, Barcelona, p. 70 .

11 El Correo Catalán, 23 de desembre de 1904.

12 Raffaela Perrone, Espacio teatral y escenario urbano. Barcelona, entre 1840 y 1923 (tesi doctoral presentada a la UPF, maig, 2011).

13 Els «precedents» de I'interès que va suscitar l'obra per als compositors musicals i els dramaturgs els desenvolupa Llorenç SOLDEVILA, «Fortuna musical i dramatúrgica de Canigó, de Jacint Verdaguer», Anuari Verdaguer, 19, 2011, p. 499501. Tant Enric Morera com Amadeu Vives es van sentir atrets pel poema. Cal destacar I'esborrany que Morera va presentar el 1908, inici d'una obra mai acabada. 
14 Gabriel Alomar, «El teatre de naturalesa», L'Esquella de la Torratxa, 1.706, Barcelona, 8 de setembre de 1911, p. 562. Alomar va escriure en diverses revistes de l'època i amb la fundació d'El Poble Català es va convertir en un dels ideòlegs principals. La suggestió musical dels seus poemes i el sentit que pren la creació poètica en relació amb la natura fa que per a ell la poesia esdevingui el punt més alt d'expressió humana. Vegeu «L'estètica arbitrària» II a El Poble Català, Barcelona,10-V-1906. Alomar assumeix el concepte messiànic del poeta, que explica de la manera següent: «El món els anomena desequilibrats, perquè han perdut la normalitat infeconda i estàtica dels satisfets. Llur reialme no es troba verament en aquest món. Stuart Mill els anomena els descontents; Spencer, els inadaptats; Nietzsche, els inactuals. Són hiperestètics, posseïts, inspirats. Llur obra comença per una gran negació, i d'entremig d'aquest pessimisme absolut, sobre les runes de lo actual, entreveuen, informulada iamorfa, però segura i esplendent, la realitat futura», El futurisme, p. 31-32.

${ }^{15}$ Ibidem, p. 562.

16 «El poema Canigó en escena», La Hormiga de Oro, 18 de juny de 1910.

17 Vegeu Josep Maria BARNILs, Figueras, cien años de ciudad, Premi literari Societat Coral Erato, 1974; Joaquim RABASEDA, Jaume Pahissa. Un cas d'anàlisi musical, tesi doctoral dirigida per Francesc ció un caràcter, que «seria la més encertada unió del sentiment artístic ab I'escena patriòtica mateixa. Jo crec que'Is poetes trobarien, sols en la poetisació d'una tal escena i del seu símbol, una font perennal de temes». ${ }^{14}$ Com veiem, Alomar advoca per una poetització de les escenes que atorga als personatges un valor simbòlic que perdura. Tanmateix, el que diferencia el fons èpic de la tragèdia grega amb el teatre líric català és la finalitat d'unir el sentiment amb la recuperació de la identitat del poble. Al seu parer, el Teatre de Natura de la Garriga va ser «una festa de civisme i solidaritat social», que de cap manera s'ha d'entendre com «una reacció de ruralisme: és una conquesta del camp per la ciutat; és una consagració del bosc primitiu a la nova Barcelona; és un brot d'olivera o de roure consagrat sobre un monument». ${ }^{15}$

\section{$L^{\prime}$ art líric dramàtic: el poema simfònic Canigón ${ }^{16}$ a les Arenes de Figueres}

L'any 1901, el compositor Jaume Pahissa estava treballant en un projecte musical sobre Canigó, del qual va estrenar El combat el 1906. I fins al 1910 va col.laborar amb Josep Carner per al Ilibret complet, obra que es pretenia estrenar a Figueres amb motiu de les fires i festes de la Santa Creu. ${ }^{17}$ Segons recull Xosé Aviñoa, els figuerencs que havien impulsat la idea d'estrenar l'obra «estaven preocupats per a coronar les festes de la vila amb un espectacle musical a l'aire lliure». ${ }^{18}$ La idea era convertir les Arenes de la vila empordanesa en una mena de "Béziers català», cosa que quedava justificada a més a més perquè ambdues viles tenien com a nexe d’unió les muntanyes del Canigó.

El nostre interès sobre l'espectacle rau en la idea de posar en relació els elements que configuren la gènesi del Teatre de Natura com a projecte en què culmina l'ideal d'art total del Modernisme. La versió teatral del poema verdaguerià va comptar amb una brillant adaptació per Josep Carner i música de Jaume Pahissa, sota la direcció de la representació escènica d'Adrià Gual. ${ }^{19}$ Una obra orquestrada globalment que s'havia d'estrenar el 3 de maig, però que una forta tramuntanada ho va impedir. Després de la destrossa dels decorats, I'estrena es va ajornar fins al 12 de juny.

Amb data de 31 de març ja s'informava dels preparatius de l'escenografia:

los renombrados escenógrafos señores Moragas y Alarma han terminado su excursión al Canigó para ultimar los detalles necesarios sobre la Abadía de San Martín que debe figurar en el decorado. ${ }^{20}$ 
De fet, és Gual qui descriu el procés de la manera següent:

Resolts els punts de vista cabdals, en fet d'adaptació literària, i de collaboració musical, va caldre pensar en aquell altre aspecte, si sempre important en fet de teatre, en aquell cas, i degut a les circumstàncies i als ambients on devia realitzar-se, d'una importància extraordinària. Em refereixo a I'escenografia, I'estudi de la qual vaig encarregar al meu amic Salvador Alarma que, demés de posseir condicions de pintor de teatre, de sobres provades, les reunia de gran tècnic teatral, cosa de totes passades indispensable en aquelles circumstàncies. ${ }^{21}$

En el programa s'hi veu una reproducció fotogràfica de l'estudi de Moragas \& Alarma pintant el decorat del poema Canigó (fig. 1). El muntatge escènic va rebre grans lloances per part de la premsa:

L'impressió que produeixen les teles d'en Moragues y Alarma, es realment meravellosa. La nota lluminosa, d'una blancor cegadora, del Canigó nevat destacantse sobre'l cel del Empordà, es encertadíssima y grandiosa. És lo millor del decorat. ${ }^{22}$

Sens dubte, va esdevenir una representació viva del poema, amb onze personatges que parlaven i quatre que cantaven, acompanyats per I'orquestra i el cos de ball del Gran Teatre del Liceu. Hi van participar un total de cinc-cents executants.

El cartell anunciador el va dissenyar Adrià Gual, com també els programes de mà. Un exemplar del llibret editat per a I'ocasió es conserva a la Biblioteca de Catalunya (fig. 2) i és una font primària fonamental que ens ha permès recompondre de manera fefaent els diferents elements que van conformar la primera mostra de Teatre de Natura, tot resseguint les traces visuals i textuals del que va ser. Les primeres fotografies que acompanyen els textos, firmades per Pau Audouard, són encapçalades, a la primera pàgina, per una panoràmica de I'escena, seguides per un retrat de cada un dels intèrprets del repartiment (que consten amb els actors de la part parlada i els cantants a la part cantada), acompanyats per I'orquestra completa i el gran cos de ball del Gran Teatre del Liceu (fig. 3 i 4). Sota el títol "Fulls de cor», Emili Graells i Castells exalta la figura de Verdaguer, article encapçalat pel darrer retrat en relleu que I'escultor Eusebi Arnau va fer del poeta (fig. 5). Graells es felicita de «la fausta nova de que Canigó fora representat a la nostra bella ciutat» $[. .$.$] «Aquella perla lite-$ raria, que primerament semblava exclusiva pel poble figuerench, avuy els barcelonins podrèm admirarla ab la seguritat de fruhir una d'aquelles coses impossibles fins de somniar». ${ }^{23}$ I és rellevant que destaqui la impor-
Cortès, Universitat Autònoma, 2006; Laura ViLARDELL, La recepció de Canigó, de Jacint Verdaguer, a Barcelona, València, Mallorca i Madrid (1886-1936), tesi doctoral dirigida per Ramon Pinyol, Universitat de Vic, 2013.

18 Xosé AviñoA, Jaume Pahissa: un estudi biogràfic $i$ crític, Barcelona, Biblioteca de Catalunya, 1996, p. 78.

19 Més tard, Adrià Gual va renegar dels anomenats Teatres de Natura com a «teatres a la fresca», segons recull Isidre Bravo en «L'espai de les imatges. Escenografia», p. 162, op. cit. nota 1.

20 «Crónica general», El Empordanès, 31 de març de 1910.

${ }^{21}$ Adrià GuAL, Mitja vida de teatre: memòries, Barcelona, Aedos, 1957, p. 251.

22 Robí, «El "Canigó" a Figueres. Notes d'un carnet», Diario de Gerona, 14 de juny de 1910.

23 Teatre de Natura. Canigó, Ilibret, conservat a la Biblioteca de Catalunya. Barcelona-Figueres, p. viI. 
${ }^{24}$ Ibidem.

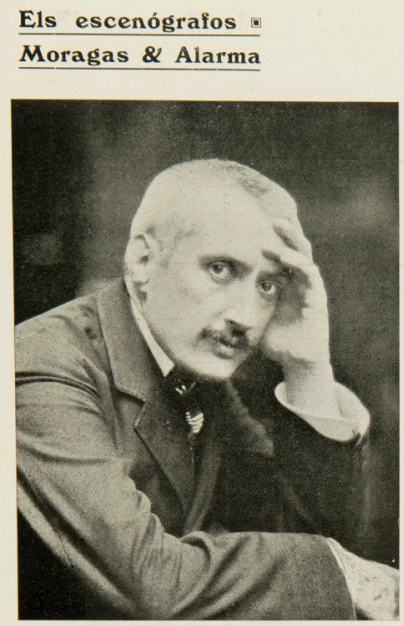

Salvador Alarma

Els escenógrafos.

Moragas \& Alarma



Miquel Moragas



Estudi den Moragas \& Alarma

Est pintant el decorat pel poema Canigó

Canigó * 13

Eot pintant

1. Estudi de Moragas \& Alarma pintant el decorat de l'obra El Canigó, llibret Teatre de Natura. Canigó, Biblioteca de Catalunya.

tància que es trobin la poesia i la música, «cisellat pel gran Verdaguer i conjuminat escènicament per un dels mellors poetas catalans: En Carner». 24 
El text de Gual intitulat «L'art escénich» és una bona síntesi en què s'expressa el concepte del Teatre de Natura. Les bases que fan possible aquest tipus de manifestació artística es troben en la simbiosi que s'ha de produir entre l'intèrpret $i$ I'espectador per mitjà d'una comunió espiritual. Segons Gual, es tractaria de desenvolupar l'emoció de les concepcions poeticoteatrals, sota l'esplendor de la natura, que descendeix vers la massa: «Dignament descendit? Com? Aquesta será I'obra del ambient, de la justa comunió, de la perfecta compenetració de lo creat y lo admirat per víes del medi, del ambient». Després d'aquest manifest sobre

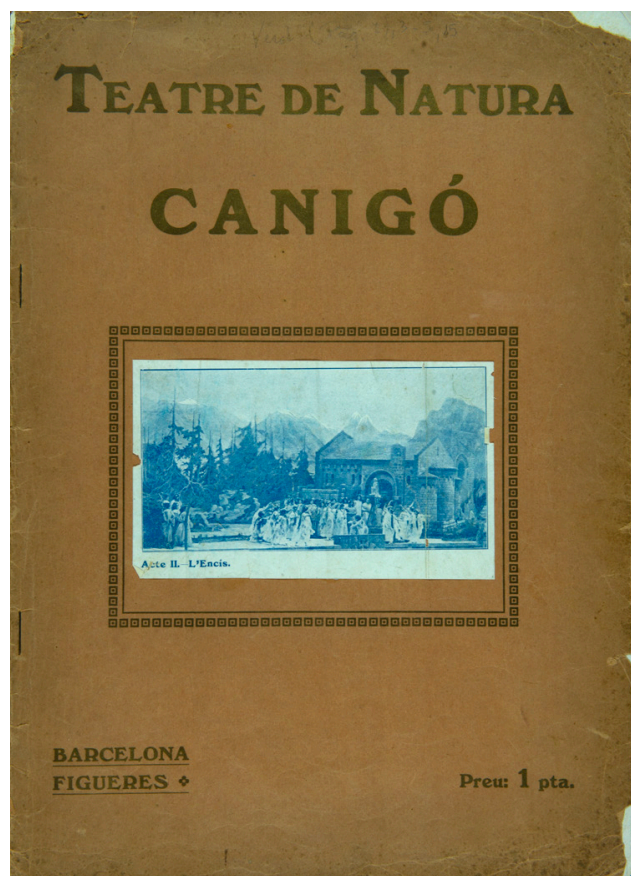

2. Portada del llibret Teatre de Natura. Canigó, Biblioteca de Catalunya. el que ha de ser l'art escènic,

I'article signat per Carles Costa presenta el tipus d'iniciativa, pròpiament dita, duta a terme a Figueres. A partir d'una vista panoràmica de la ciutat ens explica com va néixer la proposta, acompanyant I'explicació amb fotografies com la dels organitzadors de la festa (els senyors Sánchez, Montsalvatge - Josep i Jordi-, Candal i Rius) o diverses vistes de la Rambla, el passeig Nou i el mercat de granes de la capital empordanesa (fig. 6). Com un renaixement - quasi podríem dir de l'esperit de la Renaixença-, amb espectacles que «ab una alenada de reconfortant poesia, element esencial pera que les altres arts (música, dansa, pintura) puguin desenrotllarse, armonisar, y, dintre la seva deliciosa varietat, sintetisarse en I'unitat de I'obra de bellesa». ${ }^{25}$ Entre les pàgines centrals $n$ 'hi ha tres amb una fotografia i tres il|lustracions signades per Rett (RETT) dedicades a «L'aplech. Le Pélegrinage» i a «L'Encís. L'Enchantement», amb fragments del poema verdaguerià en català i francès (fig. 7). És Guerau de Liost qui evoca la figura de «Josep Carner. Poeta», acompanyat d'un retrat fotogràfic i d'un fragment manuscrit (fig. 8), que, per al tema que tractem, és del tot rellevant:

Quan les obres esceniques se juguen a l'aire Iliure y a plè sol, el públic se veu obligat a demanar grandesa als autors. L'espandiment dels «teatres de la 

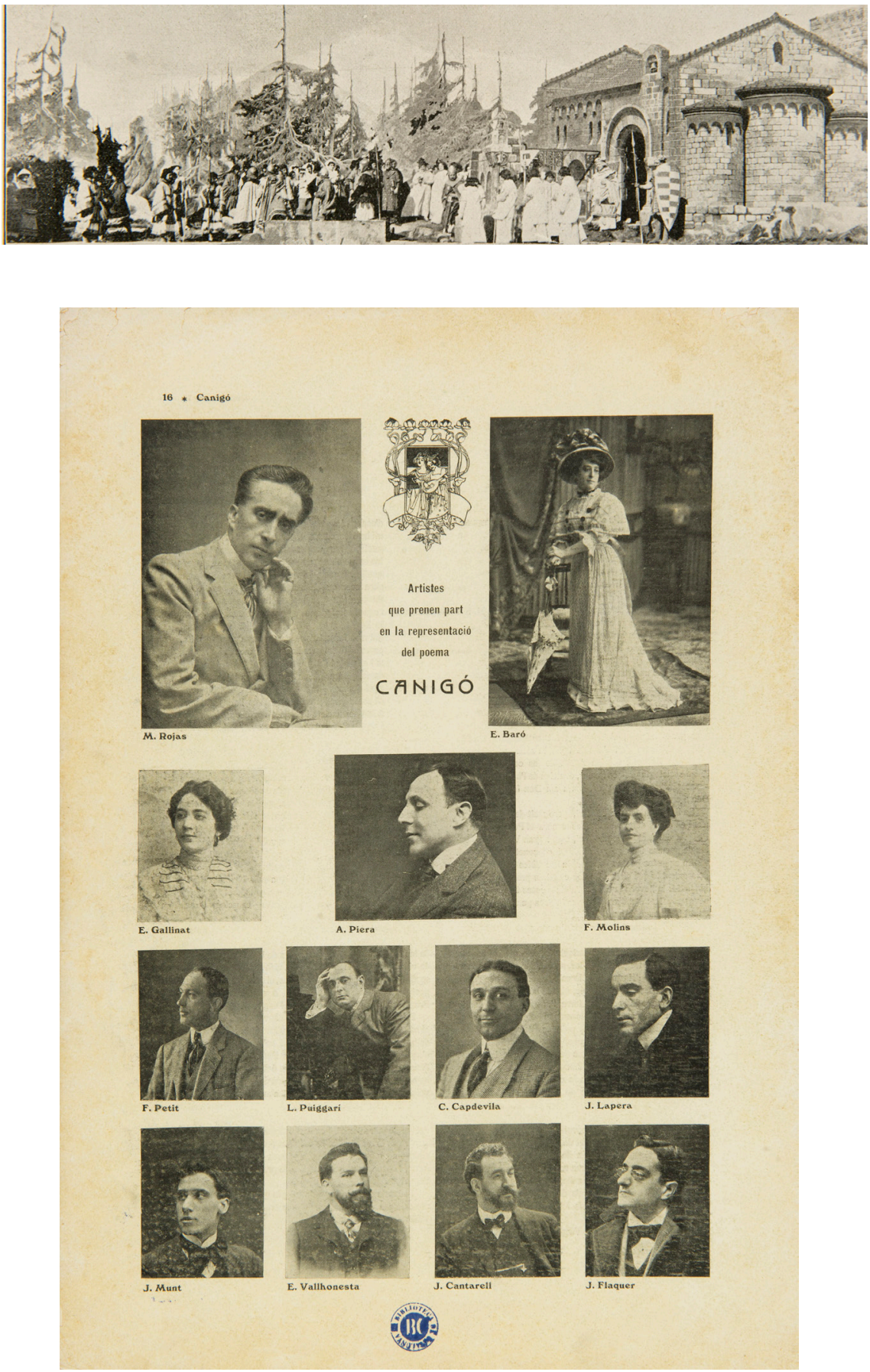

3 i 4. Fotografies fetes per Pau Audouard, una panoràmica i repartiment, llibret Teatre de Natura. Canigó, Biblioteca de Catalunya. 
natura» mataría una certa fórmula de dramaturgia que obliga a fer cavalcar lo que s'anomena tèsis sobre una anècdota insignificant. ${ }^{26}$

Pel que fa a l'escenografia, es van fer servir tot un seguit de fotografies de l'exterior, I'interior i els entorns de I'abadia de Sant Martí del Canigó, que es reprodueixen en les pàgines centrals. Podem observar-hi la presència dels escenògrafs i és plausible pensar que el fotògraf va ser el mateix Audouard (fig. 9). En les pàgines següents, la presentació de Jaume Pahissa va anar a càrrec de J. Borràs i de Palau, amb un article emmarcat per una il.lustració signada per RETT, en què sota el braç porta la partitura de I'obra, un retrat fotogràfic i un fragment de la partitura manuscrita reproduïda (fig. 10). A continuació, de la mà de J. Morató, apareix el perfil sobre «En Gual. Mestre d'escena», que destaca la importància de la revolució escènica que va dur a terme. A manera de reportatge, s'hi mostren altres fotografies de I'assaig del Canigó al teatre català, a pàgina sencera els escenògrafs al seu estudi pintant els decorats de I'obra, vistes de I'esquelet de I'escenari amb un assaig dels comparses, un esbós de la decoració, dues caricatures de Junceda de Moragas \& Alarma i una foto a la seu de I'Orfeó del Mestre Puig assajant la part musical del poema. Finalment, tanca el Ilibret un

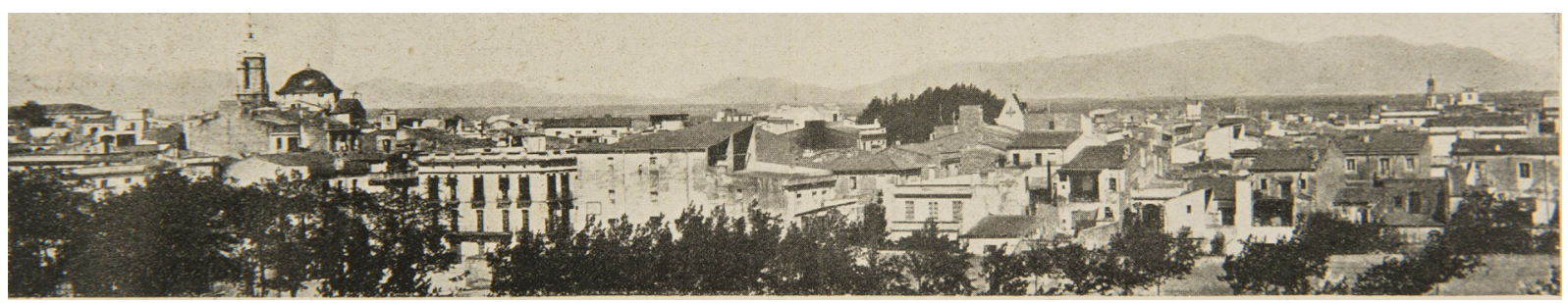

6. Vista de Figueres, llibret Teatre de Natura. Canigó, Biblioteca de Catalunya. 

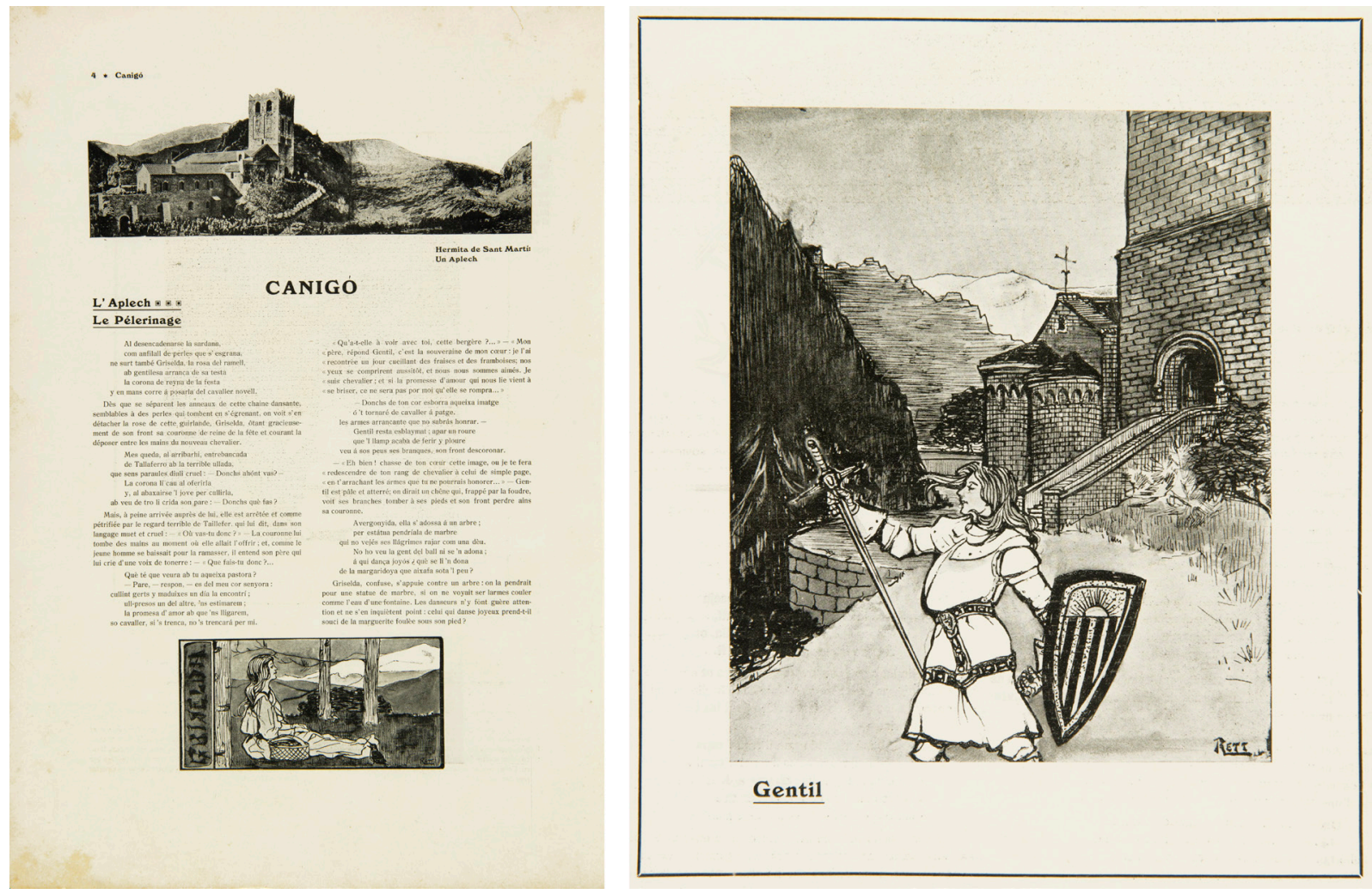

7. L’aplec i illlustracions signades per RETT, llibret Teatre de Natura. Canigó, Biblioteca de Catalunya.

article d'Eduard Marquina dedicat al poeta Jacint Verdaguer i, a tota pàgina, es reprodueixen els retrats dels artistes que participen en la representació (M. Rojas, E. Baró, E. Gallinat, A. Piera, F. Molins, F. Petit, L. Puggarí, C. Capdevila, J. Lapera, J. Munt, E. Vallhonesta, J. Cantarell i J. Flaquer).

Per a l'actuació del 19 de juny a les Arenes de Barcelona, a les 4 de la tarda, tal com consta en la contraportada del llibret, ja se n'anuncia l'estrena.

També Gual en va fer un bell cartell, amb Gentil i Griselda com a figures centrals. I per aquella ocasió excepcional, es van comercialitzar una sèrie d'imatges amb el nom de Postals Canigó. 


\section{Teatre de Natura a la Garriga}

Com bé explicita Francesc Viñas, les anomenades festes del bosc a Can Tarrés de la Garriga es poden considerar el precedent del primer Teatre de Natura de Catalunya: «Finalment, els modernistes van poder crear obres pensades exclusivament per a un veritable espai natural». ${ }^{27}$

Les dues grans representacions es van fer els anys 1911 i 1914, impulsades pel regidor de I'Ajuntament, Joan Nualart, i organitzades per «una associació integrada, principalment, per estiuejants, alguns garriguencs i per amants del teatre en general». ${ }^{28}$ En una postal d'època apareix el pòrtic d'entrada que es va construir amb les sigles TN (Teatre de Natura) on consten significativament els binomis Guimerà-Borràs/Moragas-Alarma.

Dels cercles teatrals relacionats amb L'Avenç i Catalònia, la figura d'Ignasi Iglésias es va convertir en el paradigma dels corrents ideològics més avançats del Modernisme. Després dels fets de la Setmana Tràgica (1909), el teatre d'idees i emoció, que havia obtingut tants èxits, va anar perdent interès, en gran mesura per la irrupció del Noucentisme. Les obres d'Iglésias Foc Nou, estrenada al Teatre Novetats i dirigida per Adrià Gual, i Les garses van assolir un gran ressò, van ser traduïdes al castellà i foren representades per diferents teatres de la Península i per Hispanoamèrica.

Tanmateix, amb I'empresari Ramon Franqueza i Comas del Teatre Principal de Barcelona hi van haver certes desavinences. Franqueza va denegar el permís a Iglésias per assajar Flors de cingle, que s'havia de presentar a la Garriga a I'estiu, amb I'excusa que no permetria representar obres d'autors catalans al seu teatre perquè considerava que li havien arruïnat la temporada. Aquest fet va produir una protesta unànime en els ambients teatrals i culturals de la ciutat, de tal manera que Santiago Rusiñol, Àngel Guimerà i els actors Enric Borràs i Margarida Xirgu van decidir de retirar les seves obres dels teatres. Arran d'això, va néixer l'efímer Sindicat d'Autors Dramàtics Catalans. Amb aquest epíleg controvertit, el 3 de setembre de 1911 es va estrenar Flors de cingle al bosc de Can Tarrés. El 1912, I'obra d'Ignasi Iglésias va ser editada per L'Avenç i també es va estrenar en versió castellana el 24 de febrer com a Flores de roquedal.

D'entrada, el títol ens incita a pensar en una natura esquerpa, on les flors que hi creixen es troben en un precipici de roques cantelludes. Iglésias situa l'acció a la part de dalt de la vall del Congost, als cingles de
27 Francesc VIÑAS, «El Teatre de la Natura:elsmodernistes a la Garriga», Lauro, núm. 13, 1997.

28 Ibidem. L'article recull una fotografia dels organitzadors, conservada en I'Arxiu Cuspinera. S'hi diu que hi havia el president de la junta provincial Fèlix Fages i Vilà, els garriguencs Ildefons Suñol o Juli Barbey. En fou coordinador el pintor Cast Oliver, sota la direcció artística a càrrec dels escenògrafs Alarma \& Moragas, amb la col·laboració de Maurici Vilomara i Oleguer Junyent. També I'arquitecte Manuel 


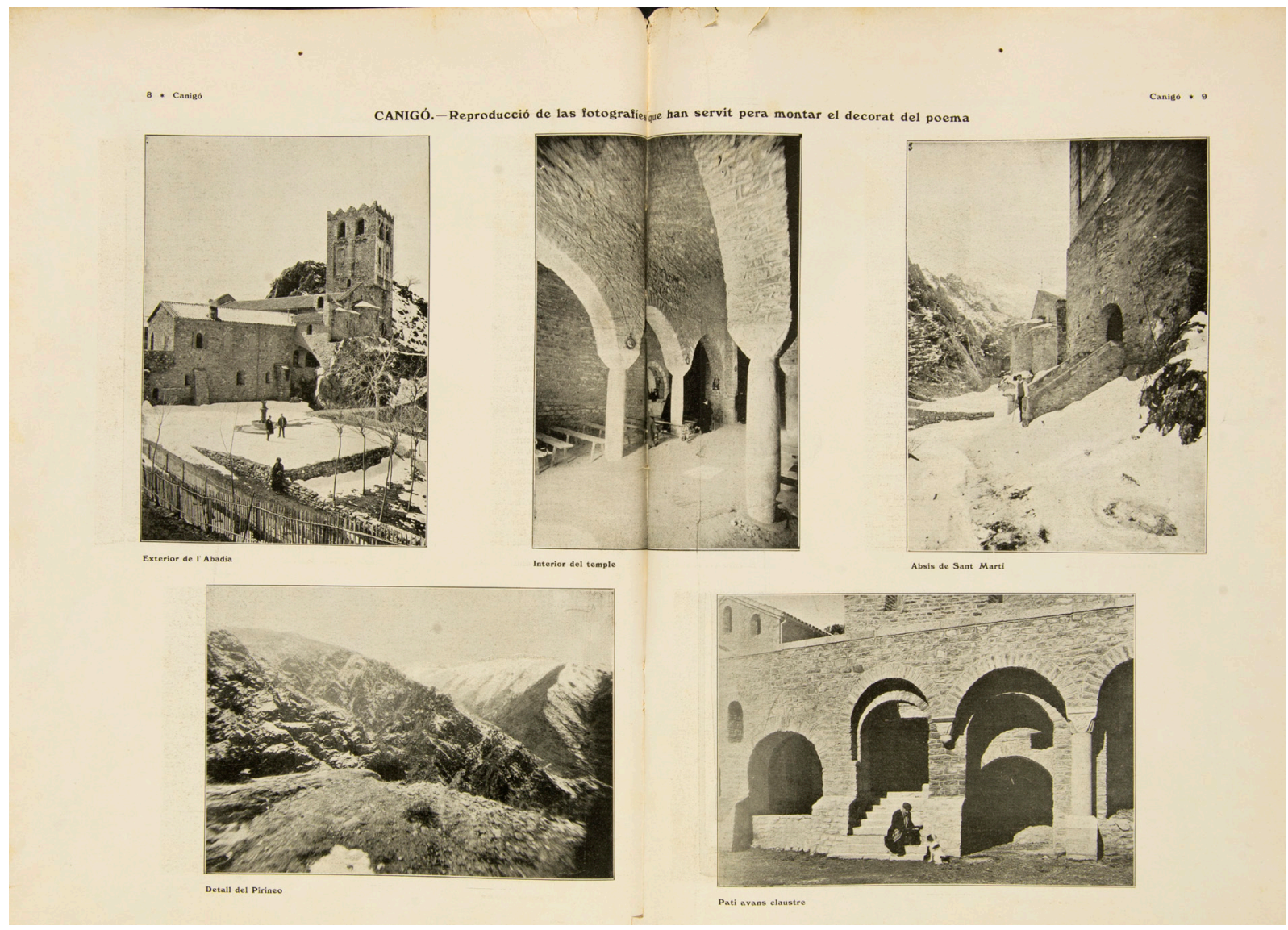

9. Fotografies de les escenografies de Sant Martí de Canigó, llibret Teatre de Natura. Canigó, Biblioteca de Catalunya.

Raspall va col·laborar en alguns aspectes relacionats amb la infraestructura tècnica.
Bertí, des d'on podem gaudir d'una vista fantàstica del massís del Montseny. Es tracta d'un poema dramàtic en vers i tres actes, amb cançons de Cassià Casademont i Busquets. El primer acte es desenvolupa en un prat florit en època primaveral. Adriana es troba amb el seu fill Segimon que està melancòlic entre les ovelles... La mare li pregunta què desitja i ell contesta: "La glòria de la terra: I'amor». La trama sobre la impossible relació amorosa entre Segimon i Pietat centra la història, que se situa en una natura simbòlica, la de la joventut enamorada, que contrasta amb la dels pares, I'Adriana i en Joanic, i la de I'àvia cega que ja no la veu. Es tracta d'una peça teatral en què els valors de la natura es corresponen amb els personatges arrelats a la terra.

La societat Alarma \& Moragas (amb Salvador Alarma i Miquel Moragas) va realitzar les decoracions escenogràfiques, mentre que el dibuixant 


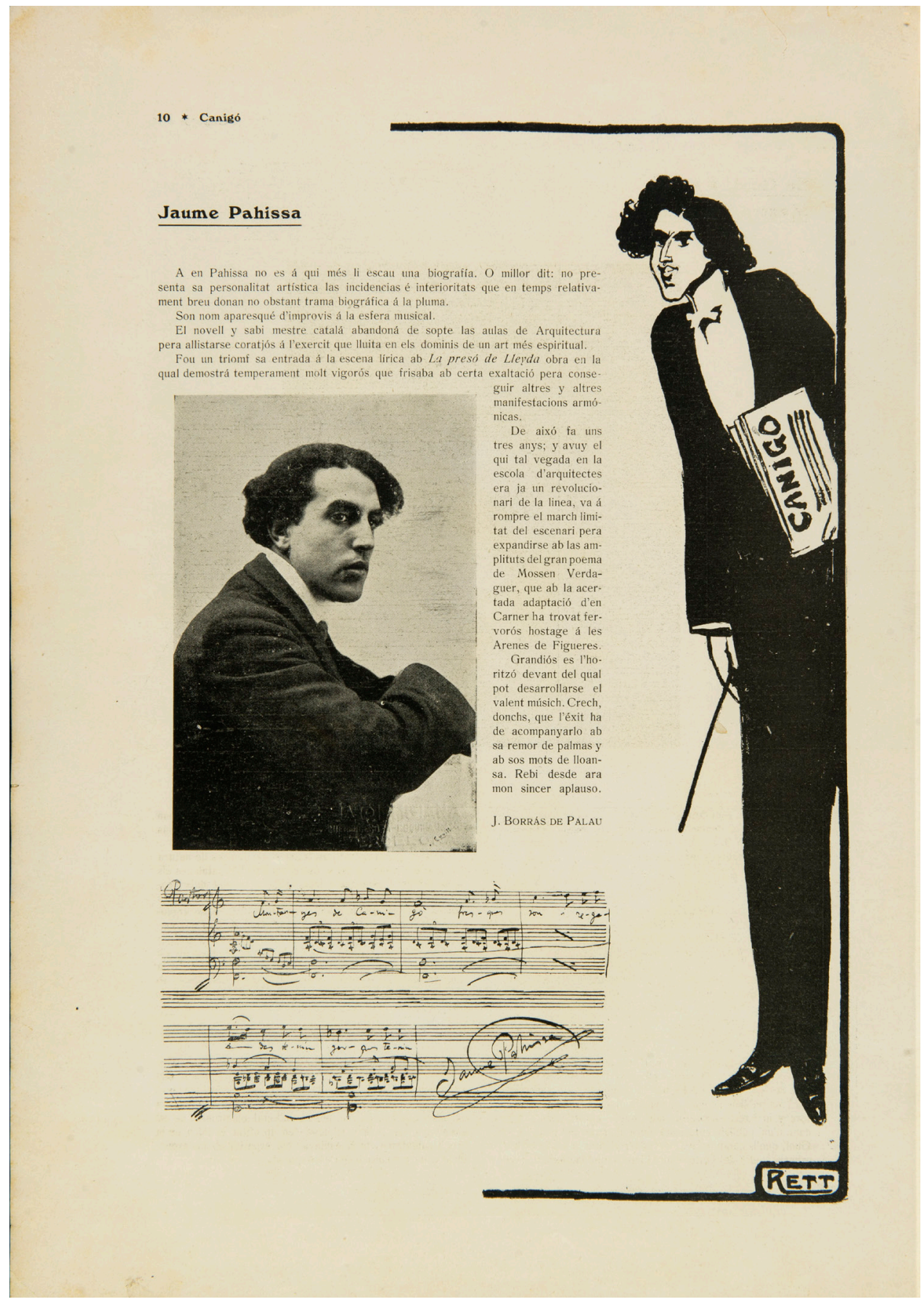

10. Presentació de Jaume Pahissa a càrrec de J. Borràs de Pau, amb illlustracions de RETT, llibret Teatre de Natura. Canigó, Biblioteca de Catalunya. 
29 La premsa del moment va publicar molts articles: " "Flors de Cingle" en la Garriga", La Publicidad, Barcelona, 4-9-1911, p. 2. B. «Teatro de la Naturaleza. En la Garriga. Estreno de Flors de Cingle, de I. Iglésias», Diario de Barcelona, núm. 247, Barcelona, 4-9-1911, p. 12266-12667. F. «Teatro de la Naturaleza». [Propera estrena de Flors de Cingle]. «En la Garriga. Flors de Cingle», Las Notícias, Barcelona, 4-9-1911, p. 1. «Teatro de la Naturaleza. En la Garriga. Estreno de Flors de Cingle», La Tribuna. Barcelona, 4-9-1911. p. 1 i 5. «Cooperadores de Ignacio Iglesias en el Teatre de la Naturalesa», La Actualidad, núm. 266. Barcelona, 5-91911.

Els articles següents reprodueixen els figurins de Mestres: "Teatro de la Naturaleza en La Garriga», La Prensa, Barcelona, 2-9-1911, p. 1 i 2. Josep M. Jordà. "Teatro de la Naturaleza. La representación de Flors de Cingle», La Tribuna, Barcelona, 1-9-1911, p. 1 i 5. L. L. "Teló enlaire. "Flors de Cingle" a la Garriga», L'Esquella de la Torratxa, Barcelona, 1-9-1911, p. 556-557.

30 Recuperat i restaurat per la Filmoteca de Catalunya, apareix erròniament datat el 1909. Número de registre 01647 (Centre de Conservació i Restauració-Documentació de la Filmoteca de Catalunya).

31 Juan Carlos DE LA MAdRID, Primeros tiempos del cinematógrafo en España, Oviedo, Universidad de Gijón, 1996. i poeta Apel-les Mestres en va fer els figurins. La confecció dels vestits i del calçat va anar a càrrec de la casa Malatesta de Barcelona, especialitzats en vestuari festiu i teatral.

La premsa se'n va fer un ampli ressò ${ }^{29}$ amb comentaris llargs i extensos. Així, per exemple, La Vanguardia descriu l'ambient i la multitud, amb uns 6.000 espectadors procedents de diferents punts del territori, que acudiren a la festa en plena natura, i a la qual van arribar amb automòbil, jardineres, tartanes o tren.

S'han conservat fragments d'un film produït per la companyia Gaumont a Barcelona, ${ }^{30}$ sota la realització del llavors jove manresà Josep Gaspar i Serra, que a quinze anys hi havia entrat a treballar i una de les primeres filmacions del qual fou el Concurso de sardanas en el Parque Güell (1907). A París es va perfeccionar com a operador i durant els tres anys següents va realitzar documentals i films d'actualitats, ${ }^{31}$ com el de la Garriga. De les seqüències que s'han conservat d'aquest pioner de la fotografia i del cinema català és significatiu que el tema central no sigui ben bé la representació de l'obra teatral: sobretot sembla tenir més interès a copsar I'ambient al voltant de I'espectacle. En primer lloc s'hi veu la gent que arriba empolainada per un passeig guarnit amb garlandes de flors. En la part següent els actors saluden. El protagonista, Enric Borràs, parla directament a càmera i va a buscar el dramaturg, Ignasi Iglésias, que defuig la filmació i mostra una certa incomoditat. Acte seguit, Gaspar filma un pastoret - amb barretina i vestit a la manera tradicional, tal com el va dibuixar Apel-les Mestres - que transita amb el seu ramat i a qui es veu pel bosc amb els escenògrafs, per donar pas a una visió de l'escena en què es poden observar alguns detalls de la representació. Tot seguit es tanca el teló, que és ben original, ja que es va fer amb fulles d'arbres. De nou, Borràs va a buscar l'autor, un Iglésias que s'escapoleix altra vegada, tot i que consta segons la premsa que va fer un breu parlament en favor del teatre en català. La imatge canvia de pla per oferir una vista panoràmica de la munió de públic assistent, entre el qual se sap que hi havia Àngel Guimerà, Santiago Rusiñol, Josep Carner, J.M. López Picó, Pompeu Crehuet i Magí Morera. A primera fila ens sembla reconèixer Apel-les Mestres, que havia dibuixat els figurins ${ }^{32}$ de I'obra (avui dia conservats al Museu de les Arts Escèniques-Institut del Teatre). Finalment, al fons hi veiem el trípode d'un fotògraf que es concentra en el que passava a l'escenari. Algunes de les imatges de I'espectacle van ser reproduïdes en la revista Comedias y comediantes, en la qual, amb data de setembre del 1911, es publica un reportatge signat per Ramón Portusach, «El Teatro de la Naturaleza. Una representación en La Garriga (Barcelona)». 
La pel-lícula es va projectar al Palacio de la Ilusión de Barcelona a les deu de la nit del mateix dia de l'estrena i es va tornar a passar al Diorama. D’aquesta manera, la crònica d'actualitat va arribar al públic barceloní en forma de noticiari Gaumont.

La segona obra del Teatre de Natura es va estrenar el 30 d'agost de 1914. Apel-les Mestres va escriure per a I'ocasió una Rondalla boscana. La viola d'or, ${ }^{33}$ text publicat per la impremta Santpere de Barcelona, que va comptar amb una música molt teatral d’Enric Morera i la direcció d'Adrià Gual.

Amb un caràcter panteista, de clara influència simbolista i amb certes reminiscències nòrdiques, I'obra se situa en un poblet a mitjan segle XVIII on els habitants estan enemistats amb l'alcalde, un personatge autoritari que vol casar la seva filla amb un comandant. Un jove trobador, que n'està enamorat, fa ballar tothom amb la seva viola d'or. I I'alcalde, enfurismat, fa empresonar el músic, el qual acaba condemnat a la forca. Llavors, com a última voluntat, toca la viola, que no para de sonar i sonar fins que és alliberat, mentre la noia l'espera enmig de I'alegria popular.

En aquesta darrera aportació de Mestres al teatre líric català, com a llibretista i dibuixant dels figurins, ${ }^{34}$ va imaginar personificacions de la natura diligent, amb la margaridoia, I'escarabat, la papallona, la campaneta, l'abella, la fada, els insectes...; uns figurins aquarel.lats que configuren un microcosmos propi, il.lustrador de la sensibilitat dels modernistes envers la meravella de la natura.

L'obra es va anunciar amb un magnífic cartell d'Oleguer Junyent i els espectadors van disposar de ventalls bellament decorats amb un programa de mà per a I'ocasió. A l'espectacle van assistir-hi el governador de BarceIona i el president de la Mancomunitat, Enric Prat de la Riba. Més tard també es representà al Teatre Principal de Barcelona. ${ }^{35}$

En resum, les arts es van conjugar en el Teatre de Natura en uns espectacles audiovisuals ben singulars, de vida curta però intensa.

Teresa-M. Sala

Universitat de Barcelona

tsala@ub.edu
32 Vegeu Isidre Bravo, L'escenografia catalana, Barcelona, Diputació de Barcelona, 1986.

33 Amb motiu del 150 aniversari del naixement d'Enric Morera, l'Associació per a la Divulgació, I'Ensenyament i la Promoció de la Música Catalana va reestrenar l'obra al Teatre de Sarrià (el 28 de juliol de 2015) i el dia 1 d'agost a la Garriga.

34 L'exposició Obrim el teló del cicle Vestigis del Modernisme, que es va dur a terme a la Fundació Abelló el 2011 i que després va itinerar per diverses institucions patrimonials, va mostrar una part d'aquests figurins.

35 Emilio Tintorer, «Semana teatral. En el Principal $L a$ violad'or, rondalla bosquetana, en tres actos de Apel.les Mestres», La Publicidad, BarceIona (octubre de 1914). 
Dins del moviment simbolista a Catalunya, Adrià Gual, Apel·les Mestres, Santiago Rusiñol i altres modernistes van seguir l'ideal de l'època de la Gesamtkunstwerk (obra d'art total). Tots aquests creadors van transitar per la plàstica, la poesia i les arts escèniques, les quals no es poden entendre sense la música. Amb el projecte del Teatre Líric català d'Enric Morera, que va comptar amb altres compositors, com ara Enric Granados i Jaume Pahissa, o I'experiència del Teatre Íntim de Gual, tots aquests artistes pretenien construir un veritable espectacle popular modern. Entre el $1910 \mathrm{i}$ el 1914, I'anomenat Teatre de Natura busca la simbiosi que ha de tenir lloc entre I'intèrpret i I'espectador.

En aquest article partim del que s'ha dit fins ara sobre el tema i, oferint nous continguts, plantegem alguns elements d'anàlisi a partir de les obres Canigó de Jacint Verdaguer, Flors de Cingle d'Ignasi Iglésias i Rondalla bosquetana. La viola d'or d'Apel-les Mestres.

Paraules clau: Gesamtkunstwerk (obra d'art total), Modernisme, arts escèniques, sinestèsies, literatura, música, escenografia, Teatre de Natura, Adrià Gual, Ignasi Iglésias, Apel-les Mestres

The arts on stage: the experience of Teatre de Natura (Nature Theatre)

Within the Symbolist movement in Catalonia, Adrià Gual, Apel-les Mestres, Rusiñol and other Modernista followed the contemporary ideal of the time of Gesamtkunstwerk. All these creators worked in fine arts, poetry and performing arts, which necessarily involved music. With the Catalan Enric Morera's Lyric Theatre project, other composers such as Enric Granados and Jaume Pahissa, or Gual's Teatre Íntim, for example, all of them tried to create a Modern popular spectacle. Between 1910 and 1914, the so-called Theatre of Nature saught to exploit the symbiosis that could occur between the performer and the audience.

In this article we start with the existing discourse and offer new content, and consider some elements of analysis from the works Canigó by Jacint Verdaguer, Flors de Cingle by Ignasi Iglésias and Rondalla bosquetana. La viola d'or by Apel-les Mestres.

Keywords: Gesamtkunstwerk, Modernisme, Arts, Literature, Music, Scenography, Teatre de Natura, Adrià Gual, Ignasi Iglésias, Apel-les Mestres 
Aquest article ha estat publicat originalment a Matèria. Revista internacional d’Art (ISSN en línia: 2385-3387)

Este artículo ha sido publicado originalmente en Matèria. Revista internacional d'Art (ISSN en línea: 2385-3387)

This article was originally published in Matèria. Revista internacional d'Art (Online ISS N: 2385-3387)

\section{MATÈRIA}

Revista internacional d'Art

Els autors conserven els drets d'autoria i atorguen a la revista el dret de primera publicació de l'obra.

Els textos es difondran amb la llicència de reconeixement de Creative Commons, la qual permet compartir I'obra amb tercers, sempre que en reconeguin I'autoria, la publicació inicial en aquesta revista i les condicions de la Ilicència: https://creativecommons.org/licenses/by/4.0/deed.ca

Los autores conservan los derechos de autoría y otorgan a la revista el derecho de primera publicación de la obra.

Los textos se difundirán con la licencia de reconocimiento de Creative Commons que permite compartir la obra con terceros, siempre que éstos reconozcan su autoría, su publicación inicial en esta revista y las condiciones de la licencia: https://creativecommons.org/licenses/by/4.0/deed.es

The authors retain copyright and grant the journal the right of first publication.

The texts will be published under a Creative Commons Attribution License that allows others to share the work, provided they include an acknowledgement of the work's authorship, its initial publication in this journal and the terms of the license: https://creativecommons.org/licenses/by/4.0/

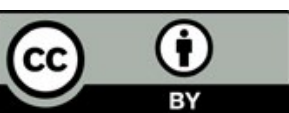

